\title{
Administration of SCH 23390 into the Medial Prefrontal Cortex Blocks the Expression of MDMA-Induced Behavioral Sensitization in Rats: An Effect Mediated by $5-\mathrm{HT}_{2 \mathrm{C}}$ Receptor Stimulation and not by $D_{1}$ Receptor Blockade
}

\author{
María Ramos', Beatriz Goñi-Allo' and Norberto Aguirre*,' \\ 'Departamento de Farmacología, Facultad de Medicina, Universidad de Navarra, Spain
}

\begin{abstract}
Akin to what has been reported for cocaine, systemic administration of the dopamine DI receptor antagonist, SCH 23390 ((R)- $(+)-7$ chloro-8-hydroxy-3-methyl- I-phenyl-2,3,4,5-tetrahydro- $\mathrm{IH}$-3-benzazepine hydrochloride), blocks the expression but not the induction of 3,4-methylenedioxymethamphetamine (MDMA)-induced behavioral sensitization. Since the medial prefrontal cortex (mPFC) appears to regulate the expression of sensitization to cocaine, this study examined whether microinjection of SCH 23390 into the mPFC would alter the expression of MDMA sensitization. Saline or MDMA was administered for 5 consecutive days. After 12 days of withdrawal, rats received a bilateral intra-mPFC microinjection of SCH 23390 or saline followed by an intraperitoneal (i.p.) challenge dose of MDMA. While SCH 23390 enhanced locomotion in MDMA-naïve rats, it completely suppressed the expression of sensitization in MDMApretreated animals. Since, $\mathrm{SCH} 23390$ has a fairly good affinity for $5-\mathrm{HT}_{2} \mathrm{C}$ receptors, we went further to study the role of mPFC DI and $5-\mathrm{HT}_{2 \mathrm{C}}$ receptors in this, apparently, paradoxical effect shown by SCH 23390. Thus, the microinjection of both SKF 8I297 (R- $(+)-6-$ chloro-7,8-dihydroxy-I-phenyl-2,3,4,5-tetrahydro- IH-3-benzazepine hydrobromide) and MK 212 (6-chloro-2-(I-piperazinyl)pyrazine hydrochloride), a DI and 5- $\mathrm{HT}_{2 \mathrm{C}}$ receptor agonist, respectively, blocked MDMA sensitization. By contrast, the 5- $\mathrm{HT}_{2 \mathrm{C}}$ receptor antagonist, RS 102221 (8-[5-(2,4-dimethoxy-5-(4-trifluoromethylphenylsulfonamido)phenyl-5-oxopentyl]-I,3,8-triazaspiro[4,5]decane2,4-dione hydrochloride), had no effect in MDMA-naïve or MDMA-sensitized animals, but reversed the effects of SCH 23390 in MDMApretreated rats. These results demonstrate that suppression of MDMA-induced sensitization by $\mathrm{SCH} 23390$ is mediated by $5-\mathrm{HT}_{2} \mathrm{C}$ receptor stimulation in the $\mathrm{mPFC}$ and not by the blockade of $\mathrm{MPFC} D \mathrm{I}$ receptors. Furthermore, these data indicate that stimulation of $5-\mathrm{HT}_{2}$ receptors by $\mathrm{SCH} 23390$ is not a minor issue and should be considered when interpreting future data. Neuropsychopharmacology (2005) 30, 2 I80-219I. doi: I0.1038/sj.npp. I300735; published online 20 April 2005
\end{abstract}

Keywords: 3,4-methylenedioxyamphetamine (MDMA, 'ecstasy'); $\mathrm{D}_{1}$ receptor; 5- $\mathrm{HT}_{2 \mathrm{C}}$ receptor; behavioral sensitization medial prefrontal cortex; SCH 23390

\section{INTRODUCTION}

Intermittent administration of psychostimulants in laboratory animals induces an enduring and progressive increase in the behavioral effects of subsequent drug injections that persists after long periods of withdrawal (Pierce and Kalivas, 1997; Wolf, 1998; Vanderschuren and Kalivas, 2000). This phenomenon, termed behavioral sensitization, has been considered for many years a useful animal model

*Correspondence: Dr N Aguirre, Department of Pharmacology, School of Medicine, University of Navarra, C/Irunlarrea, I, Pamplona 31008, Spain, Tel: + 34948 425600ext6338, Fax: + 34948425649 , E-mail: popi@unav.es

Received 30 August 2004; revised I March 2005; accepted 3 March 2005

Online publication: 4 March 2005 at http://www.acnp.org/citations/ NPP030405040396/default.pdf for the development of psychosis (Kalivas and Stewart, 1991; Pierce and Kalivas, 1997). However, recent studies have also emphasized that the neuronal plasticity underlying sensitization results in the enhancement of the incentive motivational effects of psychostimulants, which contributes to drug craving (Robinson and Berridge, 1993; Di Chiara, 1995; Robinson and Berridge, 2000).

3,4-Methylenedioxymethamphetamine (MDMA, 'ecstasy') is an amphetamine derivative that has become a very popular drug despite its potential neurotoxic effects and psychiatric complications reported in recreational MDMA users (Green et al, 2003). MDMA has the ability of lowering the threshold for rewarding intracranial self-stimulation (Hubner et al, 1988), produces conditioned place preference (Bilsky et al, 1998), and it is self-administered by rats and primates (Beardsley et al, 1986; Schenk et al, 2003). MDMA not only shares these rewarding properties with other 
psychostimulants such as amphetamine and cocaine but also elicits long-term behavioral and neurochemical sensitization in rats (Spanos and Yamamoto, 1989; Kalivas et al, 1998; McCreary et al, 1999).

Evidence has accumulated suggesting a crucial role for mesocorticolimbic dopaminergic system that projects from the ventral tegmental area (VTA) to the nucleus accumbens (NAc) and medial prefrontal cortex (mPFC), in behavioral sensitization to psychostimulants. Neuroadaptations in the VTA play an important role in the development of such phenomenon, while the NAc and $\mathrm{MPFC}$ have a key role in the expression of behavioral sensitization (Pierce and Kalivas, 1997; White and Kalivas, 1998; Wolf, 1998; Vanderschuren and Kalivas, 2000). Furthermore, many researchers have postulated that the dopamine D1 receptor is important for psychostimulant-induced behavioral sensitization (Stewart and Vezina, 1989; Kalivas and Stewart, 1991; Henry and White, 1991; Bjijou et al, 1996; Vezina, 1996). However, the role of D1 receptors appears to vary depending on the psychostimulant and the process being studied, that is, development $v s$ expression. More specifically, D1 receptor antagonist, SCH $23390((R)-(+)-7-$ chloro-8-hydroxy-3-methyl-1-phenyl-2,3,4,5-tetrahydro-1H3-benzazepine hydrochloride), blocks both the development and expression of amphetamine- and methamphetamineinduced behavioral sensitization (Vezina and Stewart, 1989; Hamamura et al, 1991; Vezina, 1996; Karper et al, 2002). In contrast, D1 receptor antagonism blocks the expression but not the development of cocaine sensitization (Mattingly et al, 1994; White et al, 1998).

We have recently shown that SCH 23390, akin to cocaine sensitization, blocks the expression but not the induction of MDMA sensitization (Ramos et al, 2004). Owing to this similarity and because the $\mathrm{mPFC}$ regulates the expression of cocaine sensitization (Pierce et al, 1998; Prasad et al, 1999; Sorg et al, 2001), in the present work we tested whether D1 receptors located in the $\mathrm{mPFC}$ could contribute to the results found in our previous study after systemic $\mathrm{SCH}$ 23390 (Ramos et al, 2004). Our results show that SCH 23390 administered into the mPFC increases the locomotor activity induced by and acute injection of MDMA (5 mg/ $\mathrm{kg}$ intraperitoneally (i.p.)), but blocks the sensitized response to a challenge dose of MDMA. SCH 23390 has been extensively used as a dopamine D1 receptor antagonist (Bourne, 2001); however, it also binds with high affinity to 5- $\mathrm{HT}_{2 \mathrm{C}}$ receptors (Briggs et al, 1991; Millan et al, 2001). For this reason, we went further to evaluate whether $5-\mathrm{HT}_{2 \mathrm{C}}$ receptor stimulation by $\mathrm{SCH} 23390$ could account for the blockade of the expression of MDMA-induced behavioral sensitization.

\section{MATERIALS AND METHODS}

\section{Drugs}

The sources of the drugs used were as follows: racemic $(+/-)$-MDMA-HCl was a gift from the 'Servicio de Restricción de Estupefacientes' (Madrid, Spain). The dose of $(+/-)$-MDMA is reported as concentration of the salt and was prepared by dissolving in physiological saline. MK 212 (6-chloro-2-(1-piperazinyl)pyrazine hydrochloride), RS 102221 (8-[5-(2,4-dimethoxy-5-(4-trifluoromethylphenylsulfonamido)phenyl-5-oxopentyl]-1,3,8-triazaspiro[4,5]decane-2,4-dione hydrochloride), and SCH 23390 were purchased from Tocris (Biogen Científica SL, Madrid, Spain). SKF 81297 ( $R$-( + )-6-Chloro-7,8-dihydroxy-1-phenyl-2,3,4,5tetrahydro-1H-3-benzazepine hydrobromide) was obtained from Sigma-Aldrich (Madrid, Spain). All solutions injected centrally were adjusted to $\mathrm{pH} 7.2$, except the solution of RS 102221, which was adjusted to $\mathrm{pH} 6-7$; control vehicle at $\mathrm{pH}$ 6-7 did not alter MDMA-stimulated locomotor activity when compared to other saline-treated groups.

\section{Animals}

Experiments were carried out in male Wistar rats (Harlan, Barcelona), weighing 260-290 g at the beginning of drug treatment. Animals were housed four per cage in constant conditions of humidity and temperature $\left(22 \pm 1^{\circ} \mathrm{C}\right)$ with a 12-h/12-h light-dark cycle (lights on at 0700). Food and water were available ad libitum. Animals were handled on the 2 days preceding the beginning of drug treatment and on 2 days preceding drug challenges. The treatment schedule for all experimental groups is shown in Table 1. All the procedures followed in the present work were in compliance with the European Community Council Directive of 24 November 1986 (86/609/EEC) and were approved by the Ethical Committee of the University of Navarra.

\section{Locomotor Sensitization Procedure}

Horizontal locomotor activity was measured in an open field, which consisted of nine square arenas $(43 \times 51 \times$ $45 \mathrm{~cm}^{3}$ ) made of black wood using a video tracking system (Ethovision 3.0, Noldus Information Technology BV, Wageningen, The Netherlands), in a softly illuminated

Table I Behavioral Sensitization Protocol and Treatment Regimens

\begin{tabular}{|c|c|c|c|c|c|c|c|}
\hline $\begin{array}{l}\text { Groups } \\
\text { (induction/day I8) }\end{array}$ & $n$ & Dayl & $\begin{array}{l}\text { Day } 2 \\
\text { (morning/evening) }\end{array}$ & $\begin{array}{l}\text { Days 3-6 } \\
\text { (morning and evening) }\end{array}$ & Day I I & Day 17 & $\begin{array}{l}\text { Day I } 8 \\
\text { (intra-mPFC/i.p.) }\end{array}$ \\
\hline Saline/saline & $7-9$ & Saline & Saline/saline & Saline & Surgery & Saline & Saline/MDMA-5 \\
\hline MDMA/saline & $8-11$ & Saline & MDMA-5/MDMA- 10 & MDMA- 15 & Surgery & Saline & Saline/MDMA-5 \\
\hline Saline/drug & $7-12$ & Saline & Saline/saline & Saline & Surgery & Saline & Drug/MDMA-5 \\
\hline MDMA/drug & $8-9$ & Saline & MDMA-5/MDMA-10 & MDMA-I5 & Surgery & Saline & Drug/MDMA-5 \\
\hline
\end{tabular}

Rats received morning injections between 0900 and 1300, while evening injections were given between 1900 and 2200 . The drugs used on day 18 were as follows:

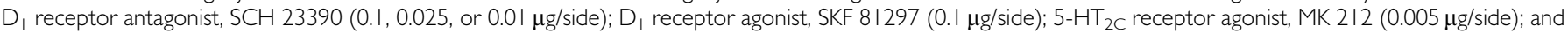
$5-\mathrm{HT}_{2 \mathrm{C}}$ receptor antagonist, RS $10222 \mathrm{I}(0.15 \mu \mathrm{g} /$ side). 
experimental room. The tracking system was set to determine the position of the animal 5 times/s. All morning experiments were conducted between 0900 and 1300 . Evening injections were given between 1900 and 2200 . Distance traveled by rats was only measured in the morning sessions of days 2 and 18 (see below).

During the whole course of the experiments, we used the MDMA administration protocol previously described by Ramos et al (2004). All rats were placed into the arenas $24 \mathrm{~h}$ prior to beginning repeated MDMA ( $15 \mathrm{mg} / \mathrm{kg}$ i.p.) or saline administrations. On this first day, rats were injected with saline $(1.0 \mathrm{ml} / \mathrm{kg}$ i.p.) and were placed into the testing arenas for a 120 min period to let animals adapt to the new environment. The next day (day 2), the subjects were divided into MDMA and saline treatment groups. Subjects were administered with either saline or MDMA $(5 \mathrm{mg} / \mathrm{kg}$ i.p.) and were placed into the arenas. Measurement of locomotor activity began after the first $15 \mathrm{~min}$. Data analysis did not begin immediately after drug administration to avoid confounds due to the injection procedure. After the habituation period, motor activity was monitored for $105 \mathrm{~min}$. In the evening, rats were injected with saline or MDMA (10 mg/kg i.p.) and were placed into the arenas for $60 \mathrm{~min}$. Over the next 4 days (days 3-6), rats received two injections of either saline or MDMA ( $15 \mathrm{mg} / \mathrm{kg}$ i.p.). The first injection was given in the morning (between 0900 and 1300), while the second one was given between 1900 and 2200. Thereafter, rats were put into the arenas for $60 \mathrm{~min}$. On day 11, rats went under surgery for cannulae implantation into the MPFC (see below). At 11 days after the last dose of MDMA or saline (day 17), rats were injected with saline and were placed into the testing arenas for a $120 \mathrm{~min}$. The next day (day 18), all the rats received an intra-mPFC infusion of either saline or the drugs under study ( $\mathrm{SCH}$ 23390, SKF 81297, MK 212, or RS 102221) followed by a challenge dose of MDMA ( $5 \mathrm{mg} / \mathrm{kg}$ i.p.). The animals were placed into the testing arenas for a $120 \mathrm{~min}$ period, where locomotor activity was quantified after the first $15 \mathrm{~min}$ habituation period. In all cases, animals were challenged only once.

\section{Surgical Procedures and Intracranial Injections}

At 1 week before the challenge dose of MDMA, rats were anesthetized with a combination of ketamine $(70 \mathrm{mg} / \mathrm{kg}$ i.p.) and xylazine ( $7 \mathrm{mg} / \mathrm{kg}$ i.p.) and placed in a Kopf stereotaxic frame, with the incisor bar set at $3.3 \mathrm{~mm}$ below the interaural line. The skull was exposed and two holes were drilled to allow implantation of two single 26-G guide cannulae (C315G Plastics1, Roanoke, VA, USA) into the mPFC according to the Atlas of Paxinos and Watson (1997) (all coordinates given relative to bregma): medial PFC, $+3.2 \mathrm{~mm}$ anteroposterior (AP), $\pm 0.7 \mathrm{~mm}$ mediolateral $(\mathrm{ML})$, and $-2.2 \mathrm{~mm}$ dorsoventral (DV). Guide cannulae were lowered into place and attached to the skull via two small stainless-steel screws and dental acrylic. Obturators (C315DC, Plastics1) cut to extend $0.5 \mathrm{~mm}$ beyond the tip of each cannula were inserted to prevent obstruction by debris. After surgery, the animals were housed individually with free access to food and water. To minimize infection, all animals were injected with the antibiotic enrofloxacin $\left(0.5 \mathrm{mg} / \mathrm{kg}\right.$ i.p.; Baytril $\left.{ }^{\mathrm{TM}}\right)$ once a day for 5 days.
On the day of the experiment (day 18), saline or the drug under study were microinjected into the mPFC using a stainless-steel 33-G internal cannula (C315I, Plastics1), connected to PE-20 tubing leading to a $10 \mu \mathrm{l}$ Hamilton syringe. The internal cannulae extended $1 \mathrm{~mm}$ below the guide cannulae bilaterally, and a volume of $0.5 \mu \mathrm{l} /$ side was delivered over a period of $1 \mathrm{~min}$. The internal cannulae were allowed to remain in place for 2 additional minutes following the injection. After $15 \mathrm{~min}$, a challenge dose of MDMA ( $5 \mathrm{mg} / \mathrm{kg}$ i.p.) was administered to the rats and the animals were placed into the arenas for $15 \mathrm{~min}$ before measurements of locomotor activity. Coordinates for local microinjections were chosen based on previous findings showing that only the prelimbic subarea, and not the infralimbic or anterior cingulate subareas of the mPFC, is involved in the expression of cocaine-induced sensitization (Pierce et al, 1998; Tzschentke and Schmidt, 2000).

\section{Verification of Cannulae Placement}

At the completion of experiments, animals were killed by decapitation, and the brains were rapidly removed and were frozen in powder dry ice. Coronal sections $(25 \mu \mathrm{m})$ were cut at the level of the PFC using a cryostat. The sections were mounted on gelatin-coated slides, stained with thionine, and placed under coverslips to verify probe placements under a light microscope by an individual unaware of the rat's behavioral response.

\section{Statistical Analysis}

Horizontal locomotor activity expressed as traveled distance $(\mathrm{cm})$ was calculated in 15-min blocks. Total horizontal activity data (a panels in Figures 1, 3-6) were analyzed with two-way ANOVA with repeated measures over days. Time-course analyses of all behavioral data (b panels in Figures 1, 3-6) were performed with a two-way ANOVA with repeated measures over time. Data from different treatment groups within 1 day were analyzed with one-way ANOVA followed by Tukey's post hoc test and data from each group within different days were analyzed with Student's $t$-test paired data.

\section{RESULTS}

\section{Local Microinjection of SCH 23390 into the MPFC Prevents the Expression of MDMA Sensitization}

As expected, the stimulant effect of a challenge dose of MDMA ( $5 \mathrm{mg} / \mathrm{kg}$ i.p.) on day 18 was significantly enhanced in the MDMA-pretreated animals compared with salinepretreated rats and with the distance traveled by these same rats on day $2(t(8)=-5.848, P<0.001)$. To examine whether blockade of $\mathrm{MPFC} D 1$ receptor stimulation would prevent the expression of MDMA-induced sensitization, SCH $23390(0.1,0.025$, or $0.01 \mu \mathrm{g} / 0.5 \mu \mathrm{l})$ was injected bilaterally into the $\mathrm{mPFC} 15 \mathrm{~min}$ before the challenge dose of MDMA on day 18. As it can be seen in Figure 1 (top panel) and Figure 2, all three doses of SCH 23390 increased locomotion in MDMA-naïve rats. By contrast, although the lowest dose of SCH 23390 tested $(0.01 \mu \mathrm{g})$ caused no remarkable effect, the infusion of the middle dose of $\mathrm{SCH}$ 

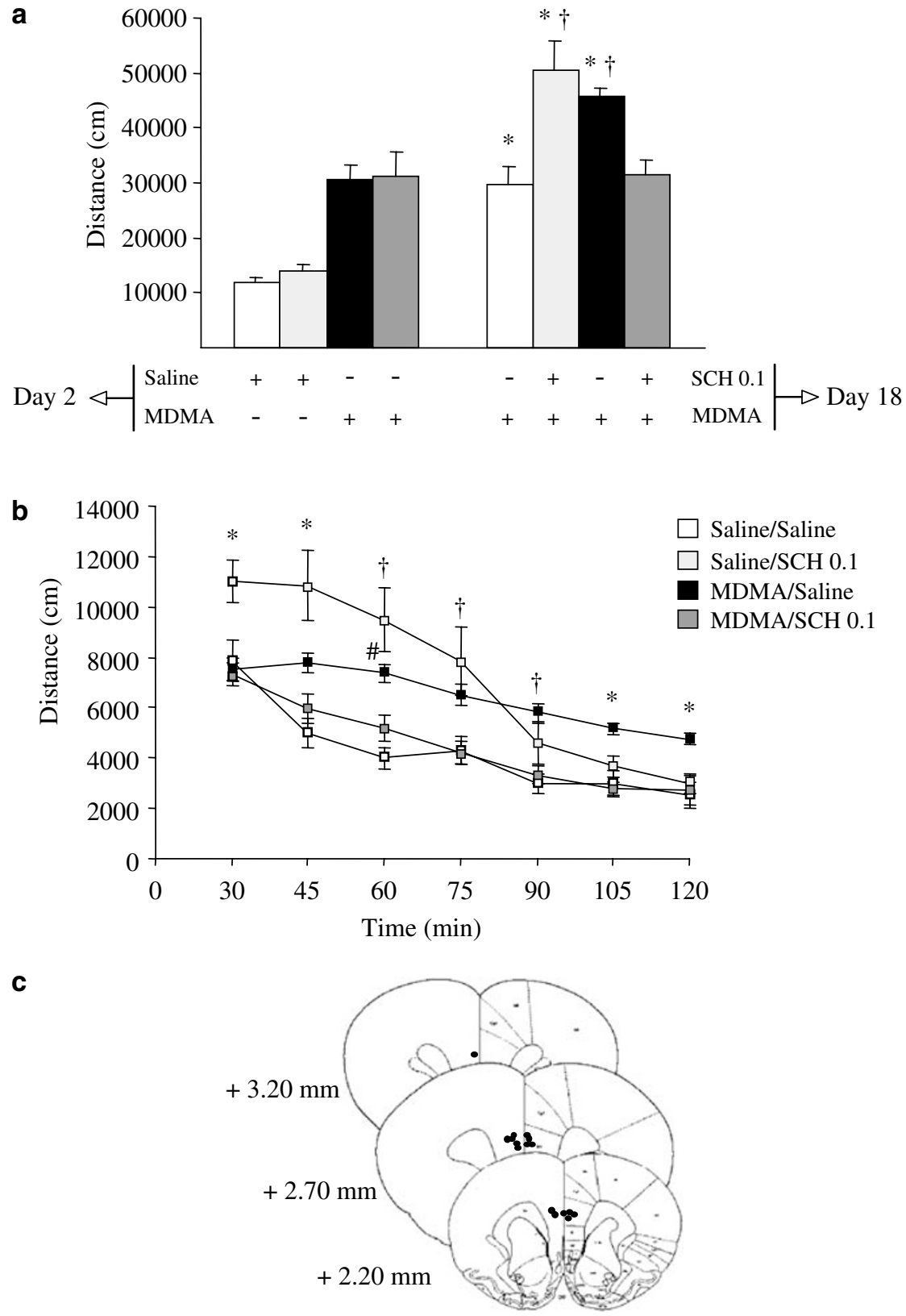

Figure I Effect of intra-mPFC infusion of SCH 23390 on the expression of MDMA-induced sensitization. The bar graph in panel a illustrates the mean \pm SEM distance traveled $(\mathrm{cm})$ over $105 \mathrm{~min}$, beginning $15 \mathrm{~min}$ after the first injection of saline or MDMA (5 mg/kg i.p.) in the morning of day 2 or the challenge dose of MDMA on day 18. The line graph in panel b shows the time course of horizontal activity in 15 min time blocks for 105 min after injecting MDMA on day 18. The data were statistically evaluated using a two-way ANOVA with repeated measures over day of injection (panel a) or time (panel b). Panel a: TreatmentF $(3,29)=10.068, p<0.001$; day $F(I, 29)=82.725, p<0.001$, interaction $F(3,29)=13.762, p<0.001$. * $p<0.05$ compared with day 2 within each treatment group; ${ }^{\dagger} p<0.05$ compared with the saline-pretreated rats on day I8. Panel b: TreatmentF(3,29) $=8.1 \mid, p<0.001$; timeF $(6, \mid 74)=83.373$, $p<0.00$ I; interactionF $(\mid 8,174)=7.469, p<0.00$ I. ${ }^{*} p<0.05$ vs the rest of the groups; ${ }^{\dagger} p<0.05$ i.saline/saline and MDMA/SCH $23390 ;{ }^{*} p<0.05$ vs saline/ saline. (c) Coronal sections taken from the Atlas of Paxinos and Watson (1997) at the level of the prefrontal cortex. The numbers indicate mm anterior to bregma. Spots correspond to the cannulae placements from the data plotted in panels a and b (group MDMA/SCH 23390).

$23390(0.025 \mu \mathrm{g})$ caused a nonsignificant trend towards the prevention of the sensitized response in MDMA-pretreated animals. Such effect reached significance in the group of rats treated with the highest dose of SCH $23390(0.1 \mu \mathrm{g})$ (Figure 1). In this last case, the two-way ANOVA for repeated measures revealed a significant interaction (treatment $\times$ time $F(18,174)=7.469, P<0.001)$. Thus, every single $15 \mathrm{~min}$ time block was analyzed using a one-way ANOVA followed by Tukey's test. Statistical differences between treatments at each time block are also shown in panel $b$ of Figure 1 .

\section{Microinjection of the Dopamine D1 Receptor Agonist SKF 81297, or the 5-HT $2 \mathrm{C}$ Receptor Agonist MK 212 into} the mPFC Prevent MDMA-Induced Sensitization

In the following set of experiments, we administered the D1 receptor agonist, SKF $81297(0.1 \mu \mathrm{g} / 0.5 \mu \mathrm{l} /$ side $)$, into the 

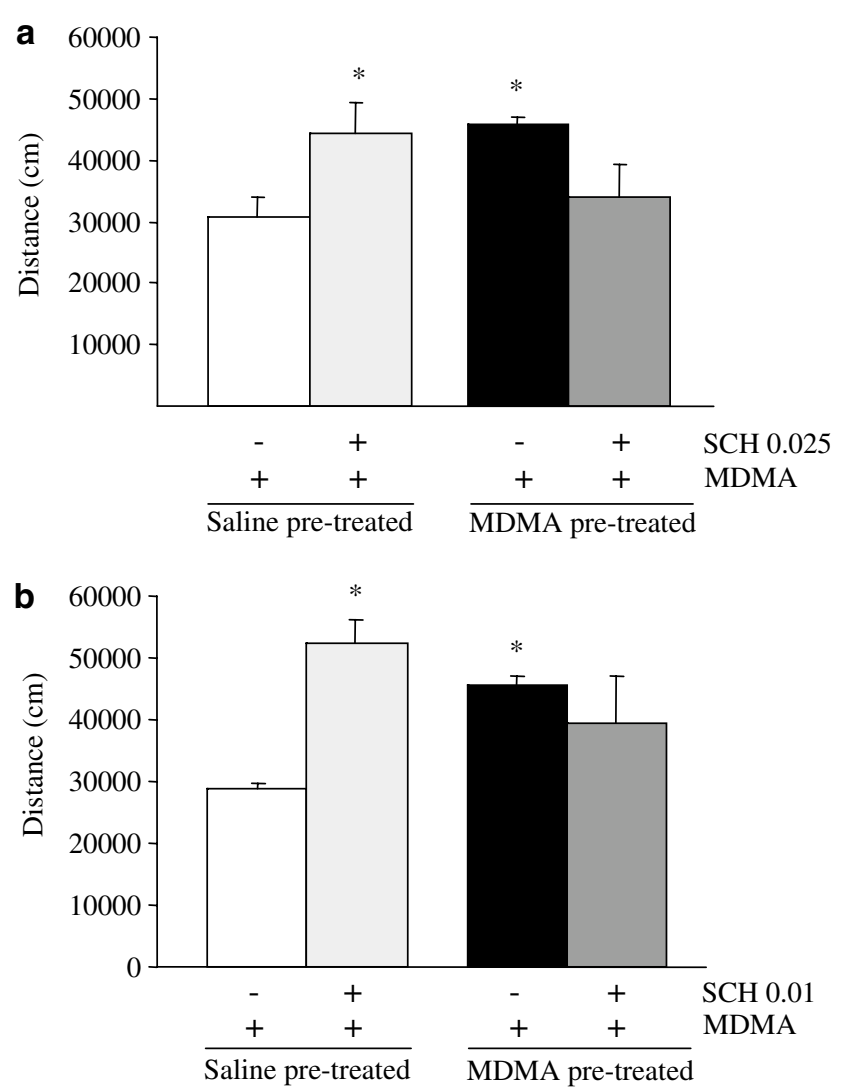

Figure 2 Effect of intra-mPFC infusion of different doses of SCH 23390 on the expression of MDMA-induced sensitization. Rats were treated with either saline or the MDMA sensitization protocol (see also Table I for further details). On day I8, an intra-mPFC microinjection of saline or $\mathrm{SCH}$ $23390(0.025 \mu \mathrm{g} / 0.5 \mu \mathrm{l} / \mathrm{side}$, panel a) or $(0.0 \mathrm{l} \mu \mathrm{g} / 0.5 \mu \mathrm{l} / \mathrm{side}$, panel b) was given. After $15 \mathrm{~min}$, rats received either saline or were challenged with a dose of MDMA (5 mg/kg i.p.). In all cases, animals were challenged only once. Data represent mean \pm SEM of distance traveled $(\mathrm{cm})$ over 105 min, beginning $15 \mathrm{~min}$ after the challenge dose of MDMA on day 18. Panel a: TreatmentF $(3,29)=4.632, p<0.01$. Panel b: TreatmentF $(3,31)=5.628$, $p<0.01$. ${ }^{*} p<0.05$ compared with saline/saline group.

mPFC. Infusion of SKF 81297, akin to SCH 23390 , completely blocked the expression of MDMA-induced behavioral sensitization, although it did not alter the activating effects of MDMA in the saline-pretreated group (Figure 3). The dose of SKF 81297 was chosen according to a previous study by Sorg et al (2001), showing that this dose of SKF 81297 blocks the expression of cocaine sensitization.

Similarly, the 5- $\mathrm{HT}_{2 \mathrm{C}}$ receptor agonist MK $212(0.005 \mu \mathrm{g} /$ $0.5 \mu \mathrm{l} /$ side) administered to MDMA-naïve animals did not affect the stimulant effects of the challenge dose of MDMA, but prevented the sensitized response in MDMA-pretreated animals (Figure 4). In this case, the dose of MK 212 was chosen based upon a previous study showing that MK 212 $(0.05 \mu \mathrm{g} / \mathrm{side})$ does not alter the activating effects of cocaine (Filip and Cunningham, 2003). Under our experimental conditions, however, such a dose did significantly attenuate the distance traveled by an acute dose of MDMA (data not shown). For this reason, we used a 10 -fold lower dose of MK 212, which, in any case, resulted in the prevention of MDMA-induced sensitization.
The Suppression of MDMA Sensitization by SCH 23390 is Reversed by Coadministration of the $5-\mathrm{HT}_{2 \mathrm{C}}$ Receptor Antagonist, RS 102221

In a final set of experiments, the $5-\mathrm{HT}_{2 \mathrm{C}}$ receptor antagonist, RS 102221, was microinjected alone or in combination with SCH 23390, 15 min before the challenge dose of MDMA on day 18. In the first case, RS 102221 $(0.15 \mu \mathrm{g} / 0.5 \mu \mathrm{l} / \mathrm{side})$ by itself did not modify the activating effects of MDMA in saline- or MDMA-pretreated animals (Figure 5). On the contrary, when RS 102221 was coinfused with SCH 23390, the blockade of MDMA sensitization by $0.1 \mu \mathrm{g}$ of SCH 23390 was reversed by RS 102221 (Figure 6). However, the combination of both drugs did not modify the acute response to MDMA in drug-naïve rats.

\section{DISCUSSION}

The main findings of our study are: (1) SCH 23390 in the $\mathrm{mPFC}$ suppresses the expression of behavioral sensitization to repeated MDMA; (2) D1 receptor activation by SKF 81297 in the mPFC also blocks the expression of MDMA sensitization; (3) these same results were achieved after $5-\mathrm{HT}_{2 \mathrm{C}}$ receptor stimulation by $\mathrm{MK} 212$; and (4) the $5-\mathrm{HT}_{2 \mathrm{C}}$ receptor antagonist, RS 102221, reverses the prevention of MDMA-induced sensitization by SCH 23390.

We have previously shown that systemic injections of the putative D1 receptor antagonist, SCH 23390, block the expression but not the induction of MDMA-induced behavioral sensitization (Ramos et al, 2004). These effects are similar to what has been previously described for cocaine (McCreary and Marsden, 1993; Mattingly et al, 1994; Tella, 1994; Martin-Iverson and Reimer, 1994; White et al, 1998). Furthermore, akin to what has also been shown for cocaine (Pierce and Kalivas, 1997), the microinjection of SCH 23390 into the core of the NAc prevents the expression of MDMA sensitization (Ramos et al, 2004). Owing to these similarities between cocaine and MDMA, and because the expression of cocaine sensitization is regulated by dopamine transmission in the mPFC (Prasad et al, 1999; Sorg et al, 2001), we went further to examine whether the local application of SCH 23390 in this brain region would also affect the expression of MDMA sensitization.

A large amount of data have implicated the glutamatergic projections arising from the mPFC to the NAc and to the VTA in the development of both amphetamine and cocaine sensitization (eg Wolf et al, 1995; Cador et al, 1999; Li et al, 1999a; see also review by Vanderschuren and Kalivas, 2000). However, while different studies have excluded any role of the $\mathrm{mPFC}$ in the expression of amphetamine sensitization (eg Li and Wolf, 1997), results from different laboratories suggest that alterations in glutamate signaling are involved in the expression of cocaine sensitization. Thus, ibotenic acid lesions of the dorsal mPFC (but not the ventral mPFC) block the expression of cocaine sensitization and the sensitized glutamate release in the NAc (Pierce et al, 1998; but see Li et al, 1999b). Furthermore, intra-mPFC microinjection of amphetamine or the D1 receptor agonist SKF 81297 prevents the expression of cocaine sensitization (Prasad et al, 1999; Sorg et al, 2001; see also Vanderschuren and Kalivas, 2000 for a review). 
a
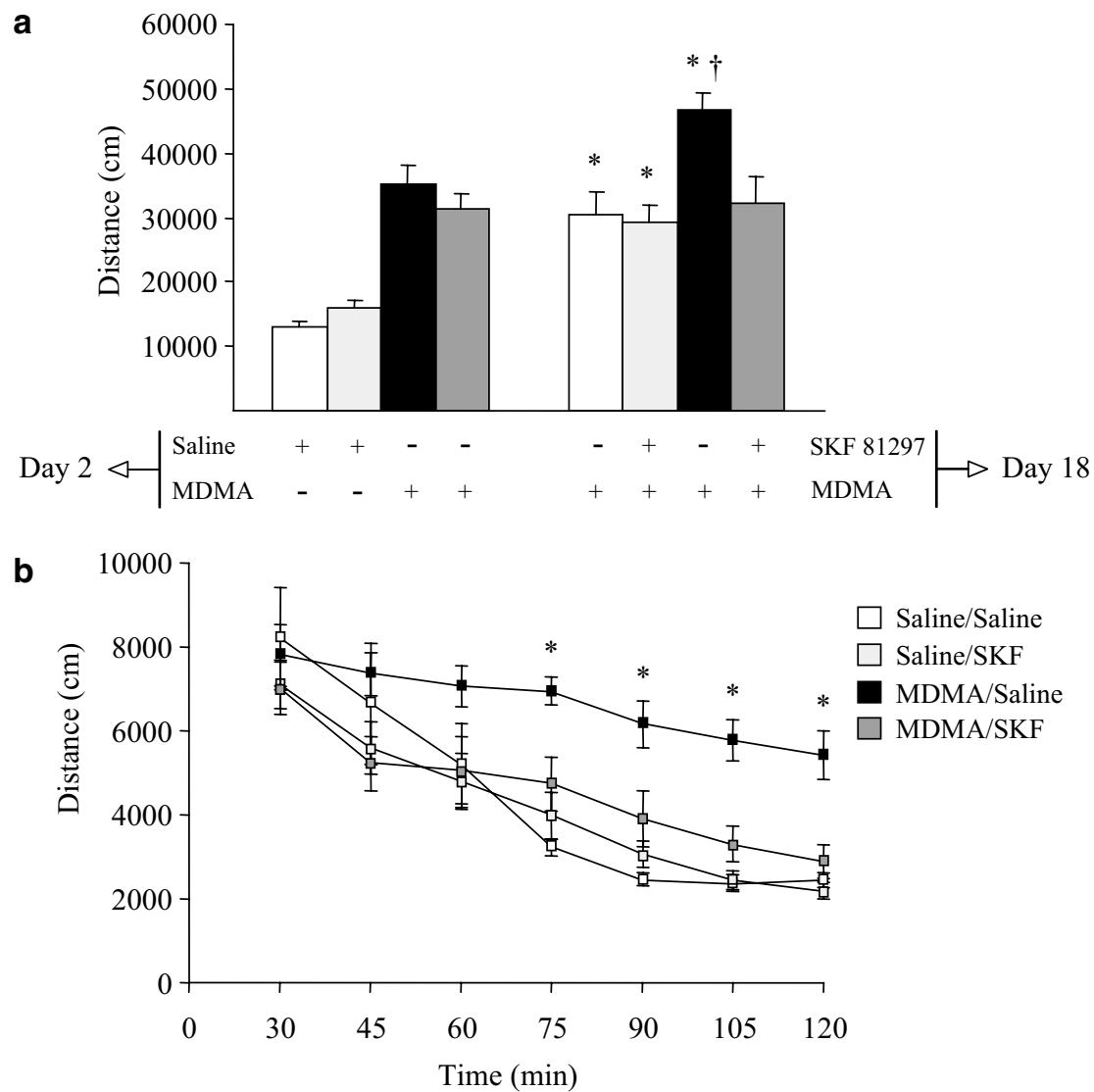

C

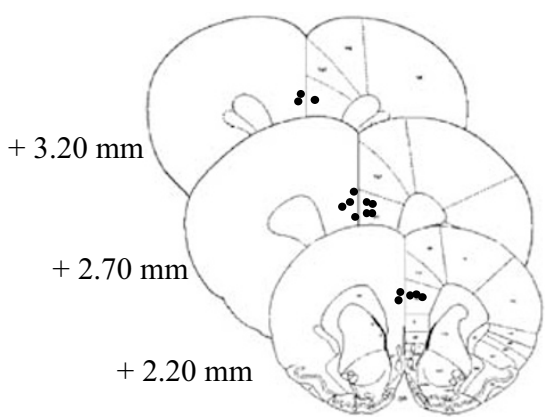

Figure 3 Effect of intra-mPFC infusion of SKF $81297(0.1 \mu \mathrm{g} / 0.5 \mu \mathrm{l} / \mathrm{side})$ on the expression of MDMA-induced sensitization. The bar graph in panel a illustrates the mean \pm SEM distance traveled $(\mathrm{cm})$ over $105 \mathrm{~min}$, beginning $15 \mathrm{~min}$ after the first injection of saline or MDMA (5 mg/kg i.p.) in the morning of day 2 or the challenge dose of MDMA on day 18. The line graph in panel b shows the time course of horizontal activity in 15 min time blocks for 105 min after injecting MDMA on day 18. The data were statistically evaluated using a two-way ANOVA with repeated measures over day of injection or time (panel b). Panel a: TreatmentF $(3,42)=15.2, p<0.001$; day $F(I, 42)=36.3, p<0.00 I$, interactionF $(3,42)=3.5, p<0.05$. $* 0<0.05$ compared with day 2 within each treatment group; ${ }^{\dagger} p<0.05$ compared with the saline-pretreated rats on day 18 . Panel b: TreatmentF $(3,42)=3.778, p<0.05 ;$ timeF $(6,252)=54.677$, $p<0.00$ I; interactionF $(18,204)=2.041, p<0.05$. ${ }^{*} p<0.05$ vs the rest of the groups. (c) Coronal sections taken from the Atlas of Paxinos and Watson (1997) at the level of the prefrontal cortex. The numbers indicate $\mathrm{mm}$ anterior to bregma. Spots correspond to the cannulae placements from the data plotted in panels a and b (group MDMA/SKF 81297).

In this study, we now report that blockade of mPFC D1 receptors with SCH 23390 increases locomotion in MDMAnaïve rats, which is in agreement with the contention that the relationship between mPFC dopamine and locomotion occurs directly by dopamine's inhibitory action on excitatory amino-acid neurons in the $\mathrm{mPFC}$. This hypothesis is congruent with the ability of cortical DA transmission for inhibiting spontaneous (Bubser and Schmidt, 1990), novelty-induced (Radcliffe and Erwin, 1996) and psychostimulant-induced (Vezina et al, 1991; Banks and Gratton,
1995; Beyer and Steketee, 2002; Steketee, 2003) locomotor activity. Our results also show that, akin to cocaine (Prasad et al, 1999; Sorg et al, 2001), the D1 receptor agonist SKF 81297 blocks the expression of MDMA-induced behavioral sensitization, providing further support for the putative inhibitory role of dopaminergic innervation of the mPFC on cortical excitatory efferent projections that innervate subcortical areas.

Accordingly, as it does in drug-naïve animals, D1 receptor blockade by SCH 23390 in the mPFC would have been 


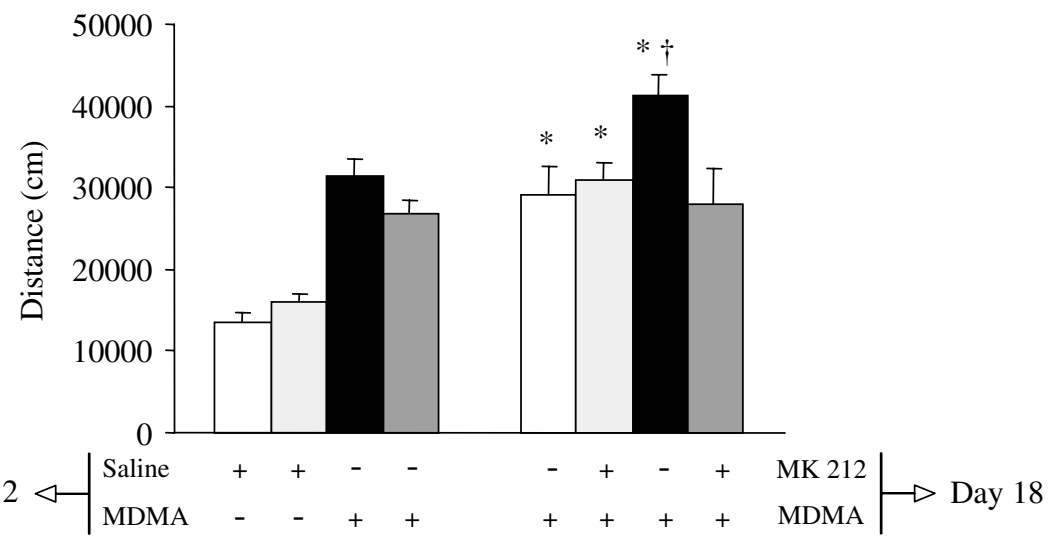

b

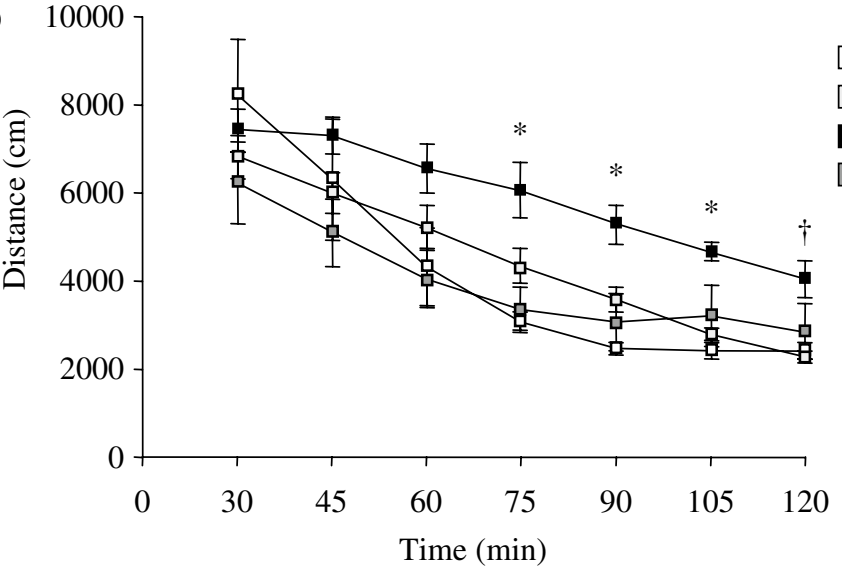

Saline/Saline

$\square$ Saline/MK 212

MDMA/Saline

$\square$ MDMA/MK 212

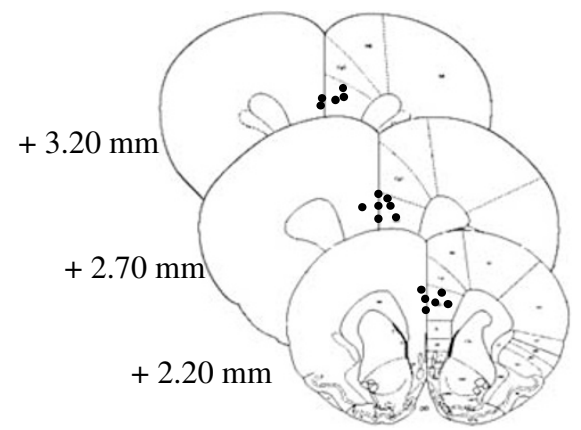

Figure 4 Effect of intra-mPFC infusion of MK-2I2 (0.005 $\mu \mathrm{g} / 0.5 \mu \mathrm{l} / \mathrm{side})$ on the expression of MDMA-induced sensitization. The bar graph in panel a illustrates the mean \pm SEM distance traveled $(\mathrm{cm})$ over $105 \mathrm{~min}$, beginning $15 \mathrm{~min}$ after the first injection of saline or MDMA (5 mg/kg i.p.) in the morning of day 2 or the challenge dose of MDMA on day 18. The line graph in panel b shows the time course of horizontal activity in 15 min time blocks for 105 min after injecting MDMA on day I8. The data were statistically evaluated using a two-way ANOVA with repeated measures over day of injection or time (panel b). Panel a: TreatmentF(3,34) = II.469, $p<0.00 I$; dayF $(I, 34)=53.825, p<0.00 I$, interactionF $(3,34)=5.555, p<0.05$. * $p<0.05$ compared with day 2 within each treatment group; $p<0.05$ compared with the saline-pretreated rats on day I8. Panel b: TreatmentF(3,34) $=4.592, p<0.05$; timeF $(6,204)=47.867, p<0.00 I$; interactionF $(I 8,252)=2.184, p<0.05 . * p<0.05$ vs the rest of the groups; ${ }^{\dagger} p<0.05$ vs saline/saline and saline/MK-2I2. (c) Coronal sections taken from the Atlas of Paxinos and Watson (1997) at the level of the prefrontal cortex. The numbers indicate mm anterior to bregma. Spots correspond to the cannulae placements from the data plotted in panels a and b (group MDMA/MK-2/2).

expected to increase locomotion in MDMA-sensitized rats and not the opposite. Then, how does SCH 23390 block MDMA sensitization? The answer probably relies on its pharmacological properties. Thus, and although taken into account in very few studies, SCH 23390 also stimulates $5-\mathrm{HT}_{2 \mathrm{C}}$ receptors, exhibiting a fairly good affinity for these receptors $\left(K_{\mathrm{i}} \approx 0.3 \mathrm{nM}\right.$ for $\mathrm{D} 1$ receptors $v s K_{\mathrm{i}} \approx 6.3 \mathrm{nM}$ for 5- $\mathrm{HT}_{2 \mathrm{C}}$ receptors; Briggs et al, 1991; Bourne, 2001; Millan et al, 2001). Iontophoretic application of 5-HT ligands suppresses spontaneous firing of PFC neurons in a $5-\mathrm{HT}_{2 \mathrm{C}}$ receptor-dependent manner (Bergqvist et al, 1999), suggesting that the $5-\mathrm{HT}_{2 \mathrm{C}}$ receptor limits the excitability of cortical pyramidal neurons (Carr et al, 2002). Therefore, it could be thought that SCH 23390 is capable of blocking MDMA sensitization by stimulating $\mathrm{mPFC} 5-\mathrm{HT}_{2 \mathrm{C}}$ receptors. The support for this hypothesis comes from our data 

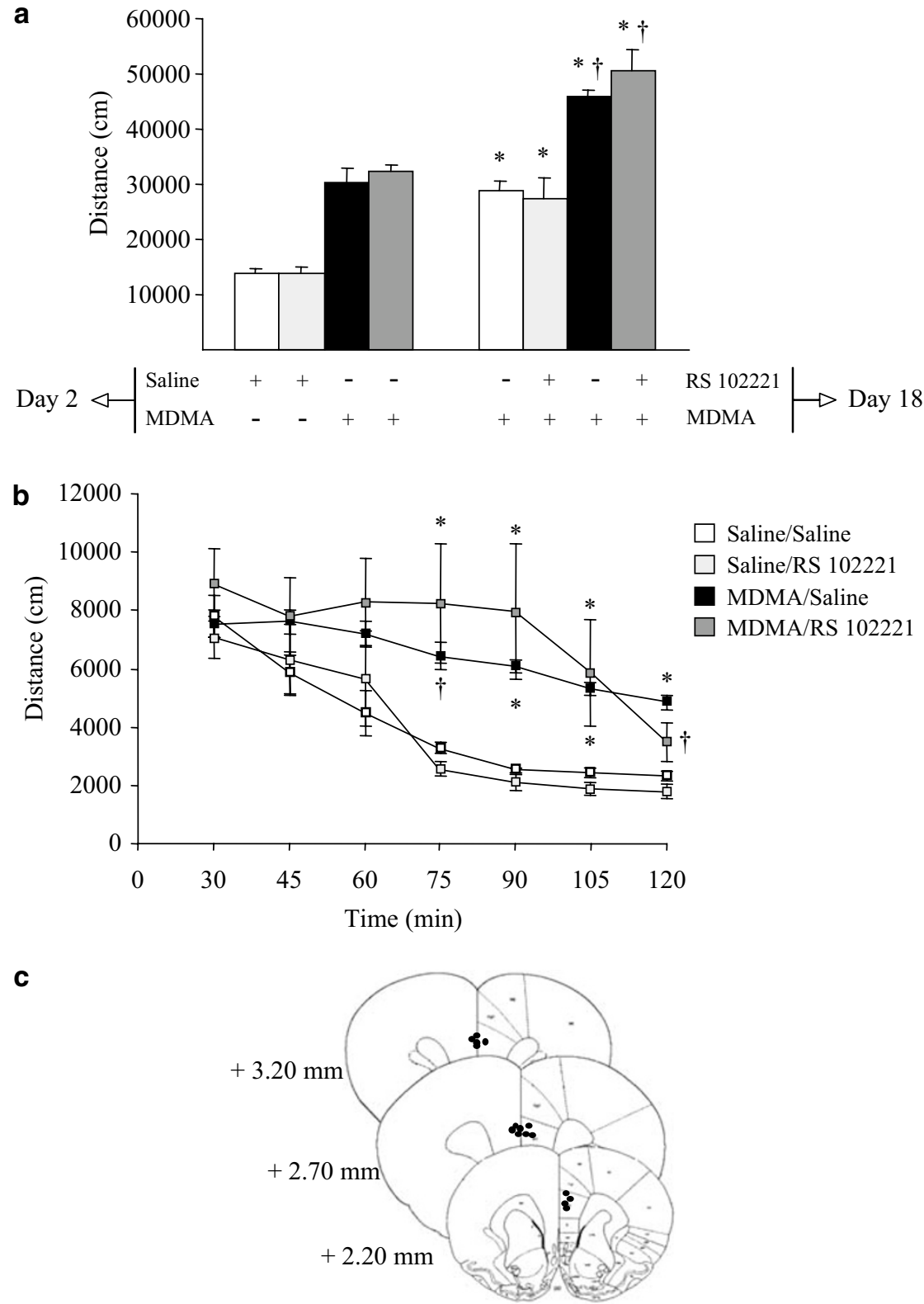

Figure 5 Effect of intra-mPFC infusion of RS I0222I (0.15 $\mu \mathrm{g} / 0.5 \mu \mathrm{l} / \mathrm{side})$ on the expression of MDMA-induced sensitization. The bar graph in panel a illustrates the mean + SEM distance traveled $(\mathrm{cm})$ over $105 \mathrm{~min}$, beginning $15 \mathrm{~min}$ after the first injection of saline or MDMA (5 mg/kg i.p.) in the morning of day 2 or the challenge dose of MDMA on day 18. The line graph in panel b shows the time course of horizontal activity in 15 min time blocks for 105 min after injecting MDMA on day 18. The data were statistically evaluated using a two-way ANOVA with repeated measures over day of injection or time (panel b). Panel a: TreatmentF(3,32) $=12.695, p<0.001$; $\operatorname{day} F(I, 32)=49.668, p<0.001$, interactionF $(3,32)=0.194$, NS. * $p<0.05$ compared with day 2 within each treatment group; ${ }^{\dagger} p<0.05$ compared with the saline-pretreated rats on day I8. Panel b: TreatmentF $(3,32)=5.357, p<0.05$; timeF $(6,192)=29.429$, $p<0.00$ I; interactionF $(18,192)=2.519, p<0.001$. ${ }^{*} p<0.05$ vs saline/saline and saline/RS I $02221 ;{ }^{\dagger} p<0.05$ vs saline/RS I 0222 I. (c) Coronal sections taken from the Atlas of Paxinos and Watson (1997) at the level of the prefrontal cortex. The numbers indicate mm anterior to bregma. Spots correspond to the cannulae placements from the data plotted in panels $a$ and b (group MDMA/RS I0222I).

showing that the $5-\mathrm{HT}_{2 \mathrm{C}}$ receptor agonist $\mathrm{MK} 212$ completely prevents the expression of sensitization in MDMA-pretreated animals.

Previous studies by Pan and Wang (1991a, b) showed that the inhibition of pyramidal cells in the prefrontal cortex produced by MDMA is mediated mainly through the serotonergic system. Moreover, it has been shown that damage produced by the neurotoxin 5,7-dihydroxytryptamine (5,7-DHT) significantly increases the inhibitory effects of serotonin on frontal cortex pyramidal cells, while the response of these cells to the iontophoresis of dopamine is attenuated (Ashby et al, 1994). Therefore, although speculative, lesions of the serotonergic terminals induced by repeated MDMA injections (Aguirre et al, 1995) could render these cells more sensitive to the inhibitory effects of $5-\mathrm{HT}_{2 \mathrm{C}}$ receptor stimulation by $\mathrm{SCH} 23390$. Further support for this contention comes from the demonstration that classical denervation supersensitivity of $5-\mathrm{HT}_{2 \mathrm{C}}$ develops 

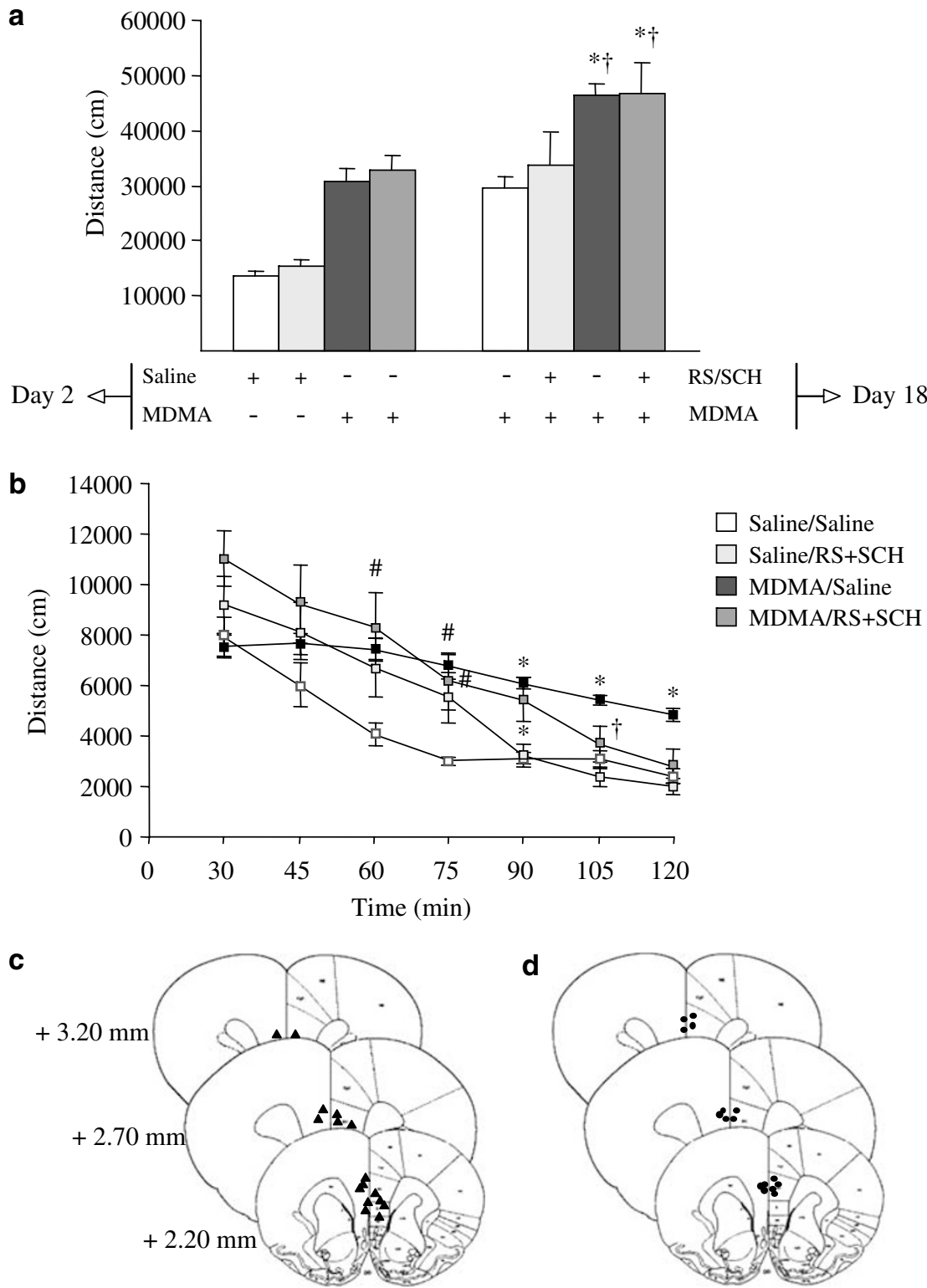

Figure 6 Effect of intra-mPFC infusion of SCH $23390+$ RS I $02221(0.1+0.15 \mu g / 0.5 \mu l / s i d e)$ on the expression of MDMA-induced sensitization. The bar graph in panel a illustrates the mean \pm SEM distance traveled $(\mathrm{cm})$ over $105 \mathrm{~min}$, beginning $15 \mathrm{~min}$ after the first injection of saline or MDMA (5 mg/kg i.p.) in the morning of day 2 or the challenge dose of MDMA on day 18 . The line graph in panel b shows the time course of horizontal activity in 15 min time blocks forl 05 min after injecting MDMA on day 18. The data were statistically evaluated using a two-way ANOVA with repeated measures over day of injection or time (panel b). Panel a: TreatmentF $(3,34)=12.442, p<0.00 \mathrm{I}$; day $\mathrm{F}(\mathrm{I}, 34)=57.898, p<0.00 \mathrm{I}$, interactionF $(3,34)=0.138, \mathrm{NS}$. ${ }^{*} p<0.05$ compared with day 2 within each treatment group; ${ }^{\dagger} p<0.05$ compared with the saline-pretreated rats on day 18 . Panel b: TreatmentF(3,34)=3.725, $p<0.05$ timeF $(6,204)=69.813, p<0.00$ I; interactionF $(18,204)=3.854, p<0.00$ I. $* p<0.05$ vs the rest of the groups; ${ }^{\dagger} p<0.05$ vs saline/RS + SCH; ${ }^{\#} p<0.05$ vs saline/saline. Panels $\mathrm{c}$ and d: Coronal sections taken from the Atlas of Paxinos and Watson (1997) at the level of the prefrontal cortex. The numbers indicate $\mathrm{mm}$ anterior to bregma. Triangles (saline-pretreated/RS 10222I + SCH 23390 group) and spots (MDMA-pretreated/RS I02221 + SCH 23390 group) correspond to the cannulae placements from the data plotted in panels a and $b$.

following depletion of 5-HT with 5,7-DHT. For example, $5-\mathrm{HT}_{2 \mathrm{C}}$ receptor ligand binding (Conn et al, 1987), the $5-\mathrm{HT}_{2 \mathrm{C}}$-like immunoreactivity (Sharma et al, 1997), and the behavioral consequences of $5-\mathrm{HT}_{2 \mathrm{C}}$ receptor stimulation (Lucki et al, 1989) are increased following 5,7-DHT pretreatment. It is also note worthy that a similar MDMA treatment as the one used in this study produces a longterm increase of $5-\mathrm{HT}_{2 \mathrm{C}}$ receptor mRNA expression in the hippocampus (Yau et al, 1994).
On the other hand, there is a large body of evidence showing that MDMA-induced 5-HT release contributes to MDMA's effect on dopamine release (Koch and Galloway, 1997). Thus, pharmacological inhibition of MDMA-induced 5-HT release attenuates MDMA-induced striatal DA release (Gudelsky and Nash, 1996; Koch and Galloway, 1997). Similarly, the nonselective $5-\mathrm{HT}_{2 \mathrm{~A} / 2 \mathrm{C}}$ receptor antagonist ritanserin attenuates MDMA-induced increases in DA release in the nigrostriatal pathway (Yamamoto et al, 
1995), while $5-\mathrm{HT}_{2 \mathrm{~A}}$ receptor activation is necessary for MDMA-induced DA release (Schmidt et al, 1992). We do not know of any previous work showing that a neurotoxic MDMA treatment similar to the one used in our experiments decreases dopamine release in the mPFC after a challenge dose of MDMA. However, in a recent study by Matuszewich et al (2002), it was shown that the depletion of 5-HT after repeated injections of MDMA leads to an attenuation of extracellular dopamine concentrations in the prefrontal cortex in response to a behavioral challenge (ie immobilization stress). These later authors suggested that the removal of the normal 5-HT-mediated inhibition of GABAergic tone on dopamine cell bodies of the VTA (Bankson and Yamamoto, 2004) may explain the inhibition of stress-induced cortical dopamine release after neurotoxic doses of MDMA. According to the above-mentioned studies, it could be speculated that 5 -HT depletion caused by the MDMA sensitization protocol would decrease the forebrain dopamine release in response to a challenge dose of MDMA. This might explain the opposite results found after SCH 23390 in drug-naïve rats vs MDMA-pretreated animals on day 18. Thus, in saline-pretreated rats, a systemic injection of MDMA would increase 5-HT and dopamine release in the mPFC. In this case, the main effect of SCH 23390 should be the blockade of $\mathrm{D} 1$ receptors and not $5-\mathrm{HT}_{2 \mathrm{C}}$ receptor stimulation. This, in turn, would increase locomotor activity (see Figures 1 and 2). By contrast, in MDMA-pretreated rats, a blunted dopamine release would occur in the $\mathrm{MPFC}$ in response to a challenge dose of MDMA. In this case, the main effect of SCH 23390 is more likely dependent on its ability to stimulate $5-\mathrm{HT}_{2 \mathrm{C}}$ receptors after a challenge dose of MDMA on day 18. This, in turn, would result in the blockade of MDMA-induced sensitization (Figure 1). This is in accordance with the data showing that the lowest dose of SCH 23390 used $(0.01 \mu \mathrm{g} /$ side $)$ was relatively ineffective at inhibiting MDMA-sensitized behavior, yet had a pronounced effect on the acute behavioral activity of MDMA. Actually, SCH 23390 increased locomotor activity without any apparent dose-response effect. By contrast, there exists a doseresponse effect of SCH 23390 in the blockade of MDMA sensitization. Owing to its affinity profile, this may reflect a more selective effect of SCH 23390 as a D1 receptor antagonist at lower doses, while higher doses of SCH 23390 are necessary to block MDMA sensitization through $5-\mathrm{HT}_{2 \mathrm{C}}$ receptor stimulation.

Our data also show that the $5-\mathrm{HT}_{2 \mathrm{C}}$ receptor antagonist RS 102221 reverses the blockade of MDMA sensitization caused by SCH 23390, further supporting our hypothesis that SCH 23390 prevents the expression of MDMA-induced sensitization by activating $\mathrm{mPFC} 5-\mathrm{HT}_{2 \mathrm{C}}$ receptors and not by blocking $\mathrm{D} 1$ receptors located in this brain region. It should be noted, however, that the RS/SCH combination did not increase locomotion in MDMA-naïve rats as it would have been expected. We do not have a clear explanation for this fact. It is known that RS 102221 or SCH 23390 injected into the NAc block the hyperactivity of cocaine and/or MDMA (McMahon et al, 2001; Filip and Cunningham, 2002; Ramos et al, 2004). It is possible then that the RS/SCH combination diffused to the Nac as some of the animals in this group exhibited cannulae placements in a very close proximity to the ventral portion of the prefrontal cortex (ie the infralimbic mPFC, see Figure $6 \mathrm{C}$ ).

Finally, it is important to note that DA in the mPFC has been shown to be a modulatory neurotransmitter (see review by Seamans and Yang, 2004). Therefore, depending on the contribution and interaction of DA with other cortical systems, including glutamate (Ramos et al, 2005) and GABA (Simantov and Peng, 2004), different responses may occur. These complex interactions between multiple neurotransmitter systems and/or brain regions warrant also consideration when interpreting the results of this and other studies.

In summary, our findings show that D1 or $5-\mathrm{HT}_{2 \mathrm{C}}$ receptor stimulation in the $\mathrm{mPFC}$ is sufficient to prevent the expression of MDMA sensitization. In a similar manner, they also indicate that the blockade of MDMA sensitization by SCH 23390 is mediated by $5-\mathrm{HT}_{2 \mathrm{C}}$ receptor stimulation excluding any role for mPFC D1 receptor blockade. Therefore, we believe that under some circumstances, the stimulation of $5-\mathrm{HT}_{2 \mathrm{C}}$ receptors by $\mathrm{SCH} 23390$ is not a minor issue and should be considered when interpreting future data. In any case, due to the popularity of this drug of abuse among young people, more studies examining the long-term consequences after repeated MDMA administration are needed.

\section{ACKNOWLEDGEMENTS}

We would like to thank the 'Asociación de Amigos de la Universidad de Navarra' and 'Fundación para la Investigación Médica Aplicada (FIMA)' for a fellowship to MR and BG-A, respectively. This work was supported by grants from the European Community (QLG3-CT2002-00809), Gobierno de Navarra, and Ministerio de Ciencia y Tecnología, Spain (BFI 2001-1602).

\section{REFERENCES}

Aguirre N, Galbete JL, Lasheras B, Del Río J (1995). Methylenedioxymethamphetamine induces opposite changes in central pre- and postsynaptic 5-HT1A receptors in rats. Eur J Pharmacol 281: 101-105.

Ashby Jr CR, Zhang JY, Edwards E, Wang RY (1994). The induction of serotonin-3 like receptor supersensitivity and dopamine receptor subsensitivity in the rat medial prefrontal cortex after the intraventricular administration of the neurotoxin 5,7-dihydroxytryptamine: a microiontophoretic study. Neuroscience 60: 453-462.

Banks KE, Gratton A (1995). Possible involvement of medial prefrontal cortex in amphetamine-induced sensitization of mesolimbic dopamine function. Eur J Pharmacol 282: 157-167.

Bankson MG, Yamamoto BK (2004). Serotonin-GABA interactions modulate MDMA-induced mesolimbic dopamine release. J Neurochem 91: 852-859.

Beardsley PM, Balster RL, Harris LS (1986). Self-administration of methylenedioxymethamphetamine (MDMA) by rhesus monkeys. Drug Alcohol Depend 18: 149-157.

Bergqvist PB, Dong J, Blier P (1999). Effect of atypical antipsychotic drugs on 5-HT2 receptors in the rat orbito-frontal cortex: an in vivo electrophysiological study. Psychopharmacology 143: 89-96.

Beyer CE, Steketee JD (2002). Cocaine sensitization: modulation by dopamine D2 receptors. Cereb Cortex 12: 526-535. 
Bilsky EJ, Montegut MJ, Nichols ML, Reid LD (1998). CGS 10746B, a novel dopamine release inhibitor, blocks the establishment of cocaine and MDMA conditioned place preferences. Pharmacol Biochem Behav 59: 215-220.

Bjijou Y, Stinus L, Le Moal M, Cador M (1996). Evidence for selective involvement of dopamine D1 receptors of the ventral tegmental area in the behavioral sensitization induced by intraventral tegmental area injections of D-amphetamine. J Pharmacol Exp Ther 277: 1177-1187.

Bourne JA (2001). SCH 23390: the first selective dopamine D1-like receptor antagonist. CNS Drug Rev 7: 399-414.

Briggs CA, Pollock NJ, Frail DE, Paxson CL, Rakowski RF, Kang $\mathrm{CH}$ et al (1991). Activation of the 5-HT1C receptor expressed in Xenopus oocytes by the benzazepines SCH 23390 and SKF 38393. Br J Pharmacol 104: 1038-1044.

Bubser M, Schmidt WJ (1990). 6-Hydroxydopamine lesion of the rat prefrontal cortex increases locomotor activity, impairs acquisition of delayed alternation tasks, but does not affect uninterrupted tasks in the radial maze. Behav Brain Res 37: 157-168.

Cador M, Bjijou Y, Cailhol S, Stinus L (1999). D-Amphetamineinduced behavioral sensitization: implication of a glutamatergic medial prefrontal cortex-ventral tegmental area innervation. Neuroscience 94: 705-721.

Carr DB, Cooper DC, Ulrich SL, Spruston N, Surmeier DJ (2002). Serotonin receptor activation inhibits sodium current and dendritic excitability in prefrontal cortex via a protein kinase C-dependent mechanism. J Neurosci 22: 6846-6855.

Conn PJ, Janowsky A, Sanders-Bush E (1987). Denervation supersensitivity of 5-HT-1c receptors in rat choroid plexus. Brain Res 400: 396-398.

Di Chiara G (1995). The role of dopamine in drug abuse viewed from the perspective of its role in motivation. Drug Alcohol Depend 38: 95-137.

Filip M, Cunningham KA (2002). Serotonin 5-HT(2C) receptors in the nucleus accumbens regulate expression of the hyperlocomotive and discrimination stimulus effects of cocaine. Pharmacol Biochem Behav 71: 745-756.

Filip M, Cunningham KA (2003). Hyperlocomotive and discriminative stimulus effects of cocaine are under the control of serotonin $(2 \mathrm{C})(5-\mathrm{HT}(2 \mathrm{C}))$ receptors in rat prefrontal cortex. J Pharmacol Exp Ther 306: 734-743.

Green AR, Mechan AO, Elliott JM, O'Shea E, Colado MI (2003). The pharmacology and clinical pharmacology of 3,4-methylenedioxymethamphetamine (MDMA, 'ecstasy'). Pharmacol Rev 55: 463-508.

Gudelsky GA, Nash JF (1996). Carrier-mediated release of serotonin by 3,4-methylenedioxymethamphetamine: implications for serotonin-dopamine interactions. J Neurochem 66: 243-249.

Hamamura T, Akiyama K, Akimoto K, Kashihara K, Okumura K, Ujike $\mathrm{H}$ et al (1991). Co-administration of either a selective D1 or D2 dopamine antagonist with methamphetamine prevents methamphetamine-induced behavioral sensitization and neurochemical change, studied by in vivo intracerebral dialysis. Brain Res 546: 40-46.

Henry DJ, White FJ (1991). Repeated cocaine administration causes persistent enhancement of D1 dopamine receptor sensitivity within the rat nucleus accumbens. J Pharmacol Exp Ther 258: 882-890.

Hubner CB, Bird M, Rassnick S, Kornetsky C (1988). The threshold lowering effects of MDMA (ecstasy) on brain-stimulation reward. Psychopharmacology 95: 49-51.

Kalivas PW, Duffy P, White SR (1998). MDMA elicits behavioral and neurochemical sensitization in rats. Neuropsychopharmacology 18: 469-479.

Kalivas PW, Stewart J (1991). Dopamine transmission in the initiation and expression of drug-and stress-induced sensitization of motor activity. Brain Res Rev 16: 223-244.
Karper PE, De la Rosa H, Newman ER, Krall CM, Nazarian A, McDougall SA et al (2002). Role of D1-like receptors in amphetamine-induced behavioral sensitization: a study using D1A receptor knockout mice. Psychopharmacology 159: 407-414.

Koch S, Galloway MP (1997). MDMA induced dopamine release in vivo: role of endogenous serotonin. J Neural Transm 104: 135-146.

Li Y, Hu X-T, Berney TG, Vartanian AJ, Stine CD, Wolf ME et al (1999a). Both glutamate receptor antagonists and prefrontal cortex lesions prevent induction of cocaine sensitization and associated neuroadaptations. Synapse 34: 169-180.

Li Y, Wolf ME (1997). Ibotenic acid lesions of prefrontal cortex do not prevent expression of behavioral sensitization to amphetamine. Behav Brain Res 84: 285-289.

Li Y, Wolf ME, White FJ (1999b). The expression of cocaine sensitization is not prevented by MK-801 or ibotenic acid lesions of the medial prefrontal cortex. Behav Brain Res 104: 119-125.

Lucki I, Ward HR, Frazer A (1989). Effect of 1-(m-chlorophenyl)piperazine and 1-( $m$-trifluoromethylphenyl)piperazine on locomotor activity. J Pharmacol Exp Ther 249: 155-164.

Martin-Iverson MT, Reimer AR (1994). Effects of nimodipine and/or haloperidol on the expression of conditioned locomotion and sensitization to cocaine in rats. Psychopharmacology 114: 315-320.

Mattingly BA, Hart TC, Lim K, Perkins C (1994). Selective antagonism of dopamine D1 and D2 receptors does not block the development of behavioral sensitization to cocaine. Psychopharmacology 114: 239-242.

Matuszewich L, Filon ME, Finn DA, Yamamoto BK (2002). Altered forebrain neurotransmitter response to immobilization stress following 3,4-methylenedioxymethamphetamine. Neuroscience 110: $41-48$.

McCreary AC, Bankson MG, Cunningham KA (1999). Pharmacological studies of the acute and chronic effects of (+)-3,4methylenedioxymethamphetamine on locomotor activity: role of 5-hydroxytryptamine(1A) and 5-hydroxytryptamine(1B/1D) receptors. J Pharmacol Exp Ther 290: 965-973.

McCreary AC, Marsden CA (1993). Cocaine-induced behaviour: dopamine D1 receptor antagonism by SCH 23390 prevents expression of conditioned sensitisation following repeated administration of cocaine. Neuropharmacology 32: 387-391.

McMahon LR, Filip M, Cunningham KA (2001). Differential regulation of the mesoaccumbens circuit by 5-hydroxytryptamine serotonin $5-\mathrm{HT}_{2 \mathrm{~A}}$ and $5-\mathrm{HT}_{2 \mathrm{C}}$ receptors. J Neurosci 21: 7781-7787.

Millan MJ, Newman-Tancredi A, Quentric Y, Cussac D (2001). The 'selective' dopamine D1 receptor antagonist, $\mathrm{SCH} 23390$, is a potent and high efficacy agonist at cloned human serotonin $2 \mathrm{C}$ receptors. Psychopharmacology 156: 58-62.

Pan HS, Wang RY (1991a). The action of (+/-)-MDMA on medial prefrontal cortical neurons is mediated through the serotonergic system. Brain Res 543: 56-60.

Pan HS, Wang RY (1991b). MDMA: further evidence that its action in the medial prefrontal cortex is mediated by the serotonergic system. Brain Res 539: 332-336.

Paxinos G, Watson C (1997). The Rat Brain in Stereotaxic Coordinates. Academic Press: New York.

Pierce RC, Kalivas PW (1997). A circuitry model of the expression of behavioral sensitization to amphetamine-like psychostimulants. Brain Res Rev 25: 192-216.

Pierce RC, Reeder DC, Hicks J, Morgan ZR, Kalivas PW (1998). Ibotenic acid lesions of the dorsal prefrontal cortex disrupt the expression of behavioral sensitization to cocaine. Neuroscience 82: 1103-1114.

Prasad BM, Hochstatter T, Sorg BA (1999). Expression of cocaine sensitization: regulation by the medial prefrontal cortex. Neuroscience 88: 765-774. 
Radcliffe RA, Erwin VG (1996). Alterations in locomotor activity after microinjections of GBR-12909, selective dopamine antagonists or neurotensin into the medial prefrontal cortex. J Pharmacol Exp Ther 277: 1467-1476.

Ramos M, Goni-Allo B, Aguirre N (2004). Studies on the role of dopamine D1 receptors in the development and expression of MDMA-induced behavioral sensitization in rats. Psychopharmacology 177: 100-110.

Ramos M, Goni-Allo B, Aguirre N (2005). Ibotenic acid lesions of the medial prefrontal cortex block the development and expression of 3,4-methylenedioxymethamphetamine-induced behavioral sensitization in rats. Behav Brain Res (available online at www.sciencedirect.com, 14 January 2005).

Robinson TE, Berridge KC (1993). The neural basis of drug craving: an incentive-sensitization theory of addiction. Brain Res Rev 18: 247-291.

Robinson TE, Berridge KC (2000). The psychology and neurobiology of addiction: an incentive-sensitization view. Addict Suppl 2: S91-117.

Schenk S, Gittings D, Johnstone M, Daniela E (2003). Development, maintenance and temporal pattern of self-administration maintained by ecstasy (MDMA) in rats. Psychopharmacology 169: 21-27.

Schmidt CJ, Fadayel GM, Sullivan CK, Taylor VL (1992). 5-HT2 receptors exert a state-dependent regulation of dopaminergic function: studies with MDL 100,907 and the amphetamine analogue, 3,4-methylenedioxymethamphetamine. Eur J Pharmacol 223: 65-74.

Seamans JK, Yang CR (2004). The principal features and mechanisms of dopamine modulation in the prefrontal cortex. Prog Neurobiol 74: 1-57.

Sharma A, Punhani T, Fone KC (1997). Distribution of the 5hydroxytryptamine $2 \mathrm{C}$ receptor protein in adult rat brain and spinal cord determined using a receptor-directed antibody: effect of 5,7-dihydroxytryptamine. Synapse 27: 45-56.

Simantov R, Peng W (2004). MDMA (ecstasy) controls in concert a group of genes involved in GABA neurotransmission. FEBS Lett 563: 3-6.

Sorg BA, Li N, Wu WR (2001). Dopamine D1 receptor activation in the medial prefrontal cortex prevents the expression of cocaine sensitization. J Pharmacol Exp Ther 297: 501-508.

Spanos LJ, Yamamoto BK (1989). Acute and subchronic effects of methylenedioxymethamphetamine $[(+/-)$ MDMA $]$ on locomotion and serotonin syndrome behavior in the rat. Pharmacol Biochem Behav 32: 835-840.

Steketee JD (2003). Neurotransmitter systems of the medial prefrontal cortex: potential role in sensitization to psychostimulants. Brain Res Rev 41: 203-228.
Stewart J, Vezina P (1989). Microinjections of Sch-23390 into the ventral tegmental area and substantia nigra pars reticulata attenuate the development of sensitization to the locomotor activating effects of systemic amphetamine. Brain Res 495: 401-406.

Tella SR (1994). Differential blockade of chronic versus acute effects of intravenous cocaine by dopamine receptor antagonists. Pharmacol Biochem Behav 48: 151-159.

Tzschentke TM, Schmidt WJ (2000). Differential effects of discrete subarea-specific lesions of the rat medial prefrontal cortex on amphetamine- and cocaine-induced behavioural sensitization. Cereb Cortex 10: 488-498.

Vanderschuren LJ, Kalivas PW (2000). Alterations in dopaminergic and glutamatergic transmission in the induction and expression of behavioral sensitization: a critical review of preclinical studies. Psychopharmacology 151: 99-120.

Vezina P (1996). D1 dopamine receptor activation is necessary for the induction of sensitization by amphetamine in the ventral tegmental area. J Neurosci 16: 2411-2420.

Vezina P, Blanc G, Glowinski J, Tassin JP (1991). Opposed behavioural outputs of increased dopamine transmission in prefrontocortical and subcortical areas: a role for the cortical D-1 dopamine receptor. Eur J Neurosci 3: 1001-1007.

Vezina P, Stewart J (1989). The effect of dopamine receptor blockade on the development of sensitization to the locomotor activating effects of amphetamine and morphine. Brain Res 499: 108-120.

White FJ, Joshi A, Koeltzow TE, Hu X-T (1998). Dopamine receptor antagonists fail to prevent induction of cocaine sensitization. Neuropsychopharmacology 18: 26-40.

White FJ, Kalivas PW (1998). Neuroadaptations involved in amphetamine and cocaine addiction. Drug Alcohol Depend 51: 141-153.

Wolf ME (1998). The role of excitatory amino acids in behavioral sensitization to psychomotor stimulants. Prog Neurobiol 54: 679-720.

Wolf ME, Dahlin SL, Hu X-T, Xue C-J, White K (1995). Effects of lesions of prefrontal cortex, amygdala, or fornix on behavioral sensitization to amphetamine: comparison with $\mathrm{N}$-methyl-Daspartate antagonists. Neuroscience 69: 417-439.

Yamamoto BK, Nash JF, Gudelsky GA (1995). Modulation of methylenedioxymethamphetamine-induced striatal dopamine release by the interaction between serotonin and c-aminobutyric acid in the substantia nigra. J Pharmacol Exp Ther 273: 1063-1070.

Yau JL, Kelly PA, Sharkey J, Seckl JR (1994). Chronic 3,4methylenedioxymethamphetamine administration decreases glucocorticoid and mineralocorticoid receptor, but increases 5-hydroxytryptamine1C receptor gene expression in the rat hippocampus. Neuroscience 61: 31-40. 